Sharif University of Technology
Scientia Iranica
Transactions E: Industrial Engineering
wCIENTIA

\title{
An extended fuzzy VIKOR for group decision-making based on fuzzy distance to supplier selection
}

\author{
A. Mahmoudi ${ }^{a, *}$, S. Sadi-Nezhad ${ }^{a}$ and A. Makui ${ }^{b}$ \\ a. Department of Industrial Engineering, Science and Research Branch, Islamic Azad University, Tehran, Iran. \\ b. Department of Industrial Engineering, Iran University of Science and Technology, Tehran, Iran. \\ Received 24 August 2014; received in revised form 11 March 2015; accepted 25 July 2015
}

\section{KEYWORDS \\ Supplier selection; \\ MADM; \\ Fuzzy VIKOR; \\ Fuzzy distance; \\ group decision- \\ making.}

\begin{abstract}
Supplier Selection Problem (SSP) has become a critical objective of purchasing departments because of its significant effect on successful logistic and Supply Chain Management (SCM). In real-life situations, SSP parameters are often imprecise, vague, uncertain, or incomplete. In this respect, fuzzy sets theory is the best developed approach to formulate these uncertainties. In this paper, we have extended fuzzy VIKOR using an efficient fuzzy distance measure to solve applicable SSP under group decision-making process. In our study, an efficient fuzzy VIKOR for solving SSP under group decisionmaking process is presented in which decision makers have different weights in decisionmaking process and their opinions are collected in the form of linguistic variables. In our methodology, preference ratio method is applied to rank the alternatives. Ultimately, several numerical illustrations and sensitivity analyses are performed to demonstrate the applicability of the proposed method.

(C) 2016 Sharif University of Technology. All rights reserved.
\end{abstract}

\section{Introduction}

Supplier selection plays a key role in achieving strategic goals of the companies. Nowadays, changing the level of customer satisfaction, general purchasing rules, and configuration of the organizations have caused us to face complicated decisions in purchasing processes [1]. Much research has been carried out on Supplier Selection Problem (SSP). Jiang et al. [2] carried out an empirical study to examine whether different supplier selection criteria and integration mechanisms could improve customer satisfaction and business performance. In the literature, SSP has been investigated in terms of Multi-Criteria Decision-Making (MCDM) and various exact and efficient heuristic methodologies are proposed for solving SSPs [3].

*. Corresponding author.

E-mail addresses: Amin.Mahmoudi10@gmail.com (A. Mahmoudi); Sadinejad@hotmail.com (S. Sadi-Nezhad); amakui@iust.ac.ir (A.Makui)
De Boer et al. [1] proposed a well-known framework for analyzing a supplier selection problem consisting of (I) problem definition, (II) formulation of criteria, (III) qualification, and (IV) choice.

In SSPs, criteria formulation is one of the most important steps to select the suppliers [4,5]. Dickson [6] presented a seminal study and introduced quality, delivery, and performance history as three most important criteria. Weber et al. [7] analyzed 74 papers on supplier selection criteria and identified price as the most cited criterion, followed by delivery and quality. Kannan and Tan and Kannan [8] investigated more than 30 selection criteria and found that on-time delivery and quality were ranked as the most important. However, in another research by FrÖdell [9], cost is the most important criterion in 12 zones of industries. Ku et al. [10] reviewed literature of SSP and summarized supplier selection criteria as cost or price, quality, service, supplier's profile, risk, buyer-supplier partnership, cultural and communication barriers, and trade restrictions. Kahraman et al. [11] presented four parts 
of SSP criteria, consisting of supplier characteristics, product efficiency, service quality, and cost.

One of the features of SSP is uncertainty in making decisions because of inherent ambiguity in evaluating qualitative criteria. Fuzzy sets theory is the most important and applicable approach to facing uncertainty in supplier selection process [12]. Fuzzy sets theory, introduced by Zadeh [13], has been presented to deal with this incomplete information and model it. In SSP, many experts utilize linguistic variables as fuzzy numbers in order to determine important features and performance of alternatives [14].

Much research concentrates on SSP in fuzzy environment. Wang et al. [15] proposed fuzzy hierarchical TOPSIS for solving a SSP. Carrera and Mayorga [16] proposed a modular fuzzy inference system approach in supplier selection for new product development. Keskin et al. [17] presented fuzzy adaptive resonance theory to evaluate and select the suppliers. Hsu et al. [18] used fuzzy preference relations with using fuzzy quality data to rank suppliers and select the best one. BüyükÖzkan and Cifci [19] developed a novel approach based on fuzzy analytic network process within multi-person decision-making schema under incomplete preference relations in sustainable supply chain. Shemshadi et al. [20] proposed fuzzy VIKOR for SSP based on entropy measure for objective weighting. Amindoust et al. [21] proposed a ranking method based on fuzzy interference system for sustainable supplier selection. BuyükÖzkan and Cifci [22] hybridized three MCDM methods including fuzzy DEMATEL, fuzzy ANP, and fuzzy TOPSIS to evaluate green suppliers. Ozaki et al. [23] described irregular ANP as minor ANP, which utilized the calculation with only the alternative matrix consisting of the missing values or the non-square matrix. Pang and Bai [24] developed a hybrid supplier evaluation approach based on the ANP and fuzzy synthetic evaluation using linguistic variables. Dursun and Karsak [25] developed a fuzzy multi-criteria group decision-making approach that made use of the Quality Function Deployment (QFD) concept for supplier selection process. Omurca [26] proposed a hybrid method of fuzzy c-means and rough set theory techniques for supplier selection, evaluation, and development problem. Boran et al. [27] proposed a TOPSIS method combined with intuitionistic fuzzy set to select appropriate supplier in group decision-making environment. Sharma and Balan [28] proposed an integrative approach considering Taguchi's loss function, TOPSIS, and Multi-criteria goal programming. Ayag and Samanlioglu [29] proposed an intelligent approach to SSP based on fuzzy ANP using uncertain human preferences as input information in the decision-making process. Carpinetti and Junior [30] combined fuzzy rule based system and TOPSIS technique to solve SSP. Cao et al. [31] proposed a TOPSIS method based on intuitionistic fuzzy judgment matrix for green supplier selection.

\section{Related works}

Compromise ranking method of VIKOR, proposed by Opricovic and Tzeng [32,33], has been developed to solve Multi-Attribute Decision-Making (MADM) problem in complex systems with non-commensurable and incompatible criteria. Recently, VIKOR method has been widely used in various applications, especially in uncertain environments, such as supplier selection [20,34-37], material selection [38-40], personnel selection [41], performance evaluation [42,43], water resources planning [44], robot selection [45], marketing [46], and waste management [47,48]. Wang and Chang [49] introduced fuzzy VIKOR for solving multicriteria group decision-making problem.

Some researchers developed fuzzy VIKOR and used it in various applications [44,50-54]. Sayadi et al. [55] proposed a VIKOR method with using interval number. Sanayei et al. [35] and Shemshadi et al. [20] used linguistic values to assess the ratings for a supplier selection problem. Kuo and Liang [42] proposed interval-value based fuzzy VIKOR. Devi [45] extended VIKOR method in intuitionistic fuzzy environment (IF-VIKOR) and then Park et al. [56] developed VIKOR method for Dynamic Intuitionistic Fuzzy Multiple-Attribute Decision-Making (DIFMADM). Wan et al. [41] extended VIKOR method with triangular intuitionistic fuzzy numbers. Chang and Wang [49] extended fuzzy VIKOR with using 2-tuple linguistic decision matrix. Liu et al. [39] proposed an interval 2-tuple linguistic VIKOR method for a material selection problem. Ju and Wang [57] considered linguistic information for both the criteria values and criteria weights. Next, thay transformed the individual linguistic decision matrix given by each decision maker into 2-tuple linguistic decision matrix, and then aggregated into collective 2-tuple linguistic decision matrix by 2-tuple linguistic arithmetic mean operation. Yücenur and Demirel [58] extended fuzzy VIKOR with uncertain Decision Maker (DM)'s degree of optimism. Minatour et al. [59] used VIKOR technique for dam site selection problem. Some papers proposed hybrid approaches of VIKOR and other techniques such as DEMATEL, ANP, and AHP for MADM problems [43,46,52,60$62]$.

\section{Preliminary concepts}

\subsection{VIKOR method}

Suppose that the set of alternatives is denoted by $a_{1}, a_{2}, \cdots a_{i}, \cdots, a_{m}(i=1, \cdots, m)$ and the set of criteria is denoted by $C_{1}, C_{2}, \cdots, C_{j}, \cdots, C_{n}(j=$ 
$1,2, \ldots, n)$. For an alternative $a_{i}$, the rating of the $j$ th criterion is asked from decision maker as $f_{i j}$.

The compromise ranking algorithm of VIKOR is briefly reviewed as follows:

1. Determine the best $f_{j}^{*}$ and the worst $f_{j}^{-}$values of all criteria, $j=1,2, \cdots, n$. If the $j$ th criterion represents a benefit, then $f_{j}^{*}=\max _{i} f_{i j}$ or setting $f_{j}^{*}$ is the aspired/desired level and $f_{j}^{-}=\min _{i} f_{i j}$ or setting $f_{j}^{-}$is the worst level;

2. Compute the values $S_{k}$ and $R_{k}, k=1,2, \cdots, n$, by the following relations:

$$
\begin{aligned}
& S_{i}=\sum_{j=1}^{n} w_{j}\left|f_{j}^{*}-f_{i j}\right| /\left|f_{j}^{*}-f_{j}^{-}\right| \\
& R_{i}=\max _{j}\left\{\left|f_{j}^{*}-f_{i j}\right| /\left|f_{j}^{*}-f_{j}^{-}\right| ; j=1,2, \cdots, n\right\}
\end{aligned}
$$

where $w_{j}$ is the weight of the $j$ th criterion expressing its relative importance;

3. Compute the value $Q_{i}, i=1,2, \cdots, m$ as:

$$
\begin{aligned}
Q_{i}= & \nu\left(S_{i}-S^{*}\right) /\left(S^{-}-S^{*}\right) \\
& +(1-\nu)\left(R_{i}-R^{*}\right) /\left(R^{-}-R^{*}\right),
\end{aligned}
$$

where:

$$
\begin{aligned}
& S^{*}=\min _{i} S_{i} \quad \text { or let } \quad S^{*}=0, \\
& S^{-}=\max _{i} S_{i} \quad \text { or let } \quad S^{-}=1, \\
& R^{*}=\min _{i} R_{i} \quad \text { or let } \quad R^{*}=0, \\
& R^{-}=\max _{i} R_{i} \quad \text { or let } \quad R^{-}=1 .
\end{aligned}
$$

Therefore, we can rewrite $Q_{i}=\nu S_{i}+(1-\nu) R_{i}$, when $S^{*}=0, S^{-}=1, R^{*}=0$ and $R^{-}=1$. $\nu$ is introduced as the weight of the strategy of "the majority of criteria" (or "the maximum group utility"), here $v=0.5$;

4. Rank the alternatives, sorting by the values $S, R$, and $Q$ in ascending order. The results are three ranking lists;

5. Propose a compromise solution as the alternative $\left(a^{\prime}\right)$, which is ranked the best by the measure $Q$ (minimum) if the following two conditions are satisfied:

(I) Acceptable advantage:

$$
Q\left(a^{\prime \prime}\right)-Q\left(a^{\prime}\right) \geq D Q,
$$

where $a^{\prime \prime}$ is the alternative with the second position in the ranking list by $Q ; D Q=1 / J-$ 1 ; and $J$ is the number of alternatives;
(II) Acceptable stability in decision-making: Alternative $a^{\prime}$ must also be the best ranked by $S$ or/and $R$.

If one of the conditions is not satisfied, then a set of compromise solutions is proposed which consists of:

- Alternatives $a^{\prime}$ and $a^{\prime \prime}$ if only condition (II) is not satisfied, or;

- Alternatives $a^{\prime}, a^{\prime \prime}, \cdots, a^{(m)}$ if condition (I) is not satisfied; and $a^{(m)}$ is determined by the relation $Q\left(a^{(m)}-Q\left(a^{\prime}\right)\right)<D Q$ for maximum $m$ (the positions of these alternatives are "in closeness").

The best alternative, ranked by $Q$, is the one with the minimum value of $Q$. The main ranking result is the compromise ranking list of alternatives and the compromise solution with the "advantage rate".

\subsection{Preliminaries of the fuzzy sets theory}

Fuzzy sets theory has been used for modeling decisionmaking processes based on imprecise and vague information such as judgment of decision makers [14].

Let $X$ be the universe of discourse, $X=$ $\left\{x_{1}, x_{2}, \cdots, x_{n}\right\}$; a fuzzy set $\tilde{A}$ of $X$ is characterized by a membership function $\mu_{\tilde{A}}(x)$ which is associated with each element $x$ in $X$, a real number in the interval $[0,1]$. The function value $\mu_{\tilde{A}}(x)$ is termed the grade of membership of $x$ in $\tilde{A}$. Some basic definitions of fuzzy sets and numbers are reviewed [63].

Definition 1. A Triangular Fuzzy Number (TFN) can be denoted as a triplet $\tilde{A}=\left(a_{1}, a_{3}, a_{3}\right)$; the membership function of the fuzzy number $\tilde{A}$ is taken as:

$$
f_{\tilde{A}}(x)= \begin{cases}\left(x-a_{1}\right) /\left(a_{2}-a_{1}\right) ; & a_{1} \leq x \leq a_{2} \\ 1 ; & x=a_{2} \\ \left(a_{3}-x\right) /\left(a_{3}-a_{2}\right) ; & a_{2} \leq x \leq a_{3} \\ 0 ; & \text { otherwise }\end{cases}
$$

Definition 2. $\tilde{m}=(a, b, c)$ is called a positive TFN if $a \geq 0 . a, b$, and $c$ are not identical.

Definition 3. Let $\tilde{A}$ and $\tilde{B}$ be two positive fuzzy numbers parameterized by the triplets $\left(a_{1}, a_{2}, a_{3}\right)$ and $\left(b_{1}, b_{2}, b_{3}\right)$ and $r$ be a positive scalar; the operations (addition, subtraction, multiplication, and division) of TFN can be performed as:

$$
\begin{aligned}
& \tilde{A}(+) \tilde{B}=\left(a_{1}+b_{1}, a_{2}+b_{2}, a_{3}+b_{3}\right), \\
& \tilde{A}(-) \tilde{B}=\left(a_{1}-b_{3}, a_{2}-b_{2}, a_{3}-b_{1}\right), \\
& \tilde{A}(\times) \tilde{B}=\left(a_{1} b_{1}, a_{2} b_{2}, a_{3} b_{3}\right), \\
& \tilde{A}(\div) \tilde{B}=\left(a_{1} / b_{3}, a_{2} / b_{2}, a_{3} / b_{1}\right),
\end{aligned}
$$




$$
\tilde{A}(\times) r=\left(r a_{1}, r a_{2}, r a_{3}\right) .
$$

\subsection{Fuzzy distance}

Many proposed methods for measuring distance between fuzzy numbers obtain a crisp value for distance between fuzzy numbers [64]. Moreover, a logical and acceptable consequence of defining a fuzzy distance measure for generalized fuzzy numbers is that the distance between two uncertain numbers should also be an uncertain and fuzzy number [65].

Voxman [66] for the first time introduced a fuzzy distance measure between two fuzzy numbers based on $\alpha-c u t$ and also stated how it was possible for the distance between two fuzzy numbers to be a crisp number. Chakraborty and Chakraborty [67] proposed another fuzzy distance in which the general fuzzy number was calculated by LR-Type fuzzy. Its main logical disadvantage is that this distance will be negative in some cases when calculated from the left point. To solve this problem, Guha and Chakraborty [68] introduced a new distance for general fuzzy numbers through using the $\alpha$-cut concept. Allahviranloo et al. [69] proposed a method based on $\alpha-c u t$ for calculating fuzzy distance between two trapezoidal fuzzy numbers.

Recently, Sadi-Nezhad et al. [70] proposed a method to compute fuzzy distance between two TFNs. Their method, in addition to covering disadvantages of past methods, had a simple mechanism. They only used the left, middle, and right points and developed their method for $K$-dimensional space. The result of this approach is a positive TFN which indicates the fuzzy distance between any two TFNs; also, when two fuzzy numbers are overlapped, this fuzzy distance includes zero value. Because of the mentioned reasons, we use fuzzy distance method, proposed by SadiNezhad et al. [70], in our extended fuzzy VIKOR.

Let $\tilde{X}=\left(x_{1}, x_{2}, x_{3}\right)$ and $\tilde{Y}=\left(y_{1}, y_{2}, y_{3}\right)$ be two TFNs. In Sadi-Nezhad et al. [70], $D_{X Y}=\left(d_{1}, d_{2}, d_{3}\right)$ is defined as a fuzzy distance between $\tilde{X}$ and $\tilde{Y}$ in the following equation:

$$
\begin{aligned}
& d_{1}= \begin{cases}\max \left\{x_{1}-y_{3}, 0\right\} ; & x_{2} \geq y_{2} \\
\max \left\{y_{1}-x_{3}, 0\right\} ; & x_{2} \leq y_{2}\end{cases} \\
& d_{2}=\left|x_{2}-y_{2}\right|, \\
& d_{3}=\left\{\max \left(y_{3}-x_{1}, x_{3}-y_{1}\right)\right\} .
\end{aligned}
$$

Figure 1 graphically shows the mentioned equation for fuzzy distance. More details and various examples can be found in their paper [70].

\subsection{Ranking fuzzy numbers}

In many cases, especially in MADM problem, ranking of fuzzy numbers is an important component in the decision-making process. Many methods have been

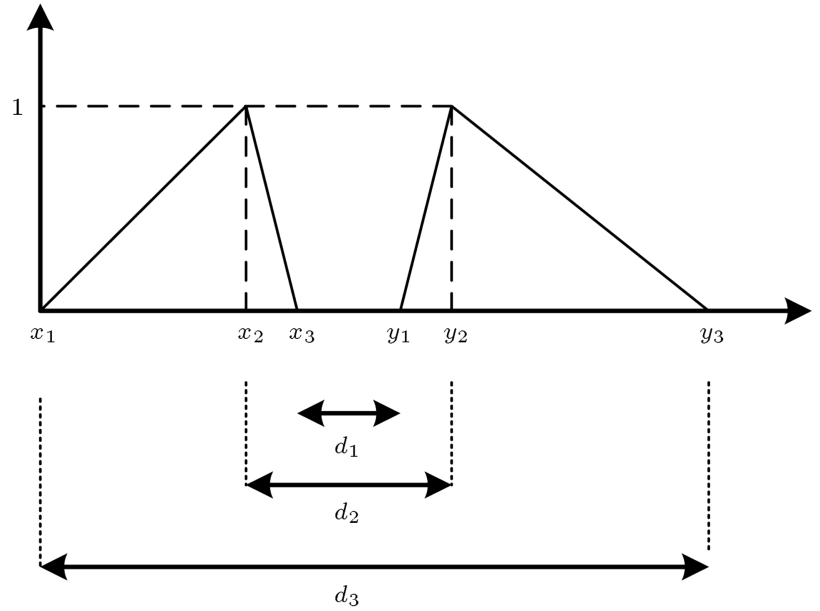

Figure 1. Fuzzy distance measure.

proposed for ranking fuzzy numbers that can be found in a brief review in paper [71]. In this paper, the method of ranking fuzzy numbers proposed by Modarres and Sadi-Nezhad [72], namely preference ratio (Pr), is used. In this method, fuzzy numbers are evaluated point by point and ranked at each point. Then, the overall preference over all points is calculated. Therefore, in this method, the numbers are compared relatively and not absolutely. More details of computation procedure can be found in their paper [73]. For two fuzzy numbers, $\tilde{N}_{1}$ and $\tilde{N}_{2}$, Modarres and SadiNezhad [74] developed an algorithm to find scalar $K$ such as:

$$
\tilde{N}_{1} \stackrel{\operatorname{Pr}}{\equiv} K \times \tilde{N}_{2} .
$$

Sadi-Nezhad and Ghaleh-Assadihave [75] proposed an algorithm based on preference ratio to rank $n$ TFNs as follows:

$$
\text { Let } \tilde{N}_{1}, \tilde{N}_{2}, \cdots, \tilde{N}_{n} \text { be as } n \text { TFNs. }
$$

Step 1: Calculate $\tilde{N}_{\text {sum }}=\sum_{i=1}^{n} \tilde{N}_{i}$

Step 2: Find scalar $K_{i}$ such as

$$
\tilde{N}_{i} \stackrel{\text { Pr }}{\equiv} K_{i} \times \tilde{N}_{\text {sum }} \text { for } i=1,2, \cdots, n \text {; }
$$

Step 3: $\quad$ Sort $K_{i}$ and, respectively, $\tilde{N}_{i}$.

\section{Research gaps}

Supplier evaluation and selection process has a critical role and significant impact on purchase management in supply chain. It is also a complicated MCDM problem with several conflicting criteria. Many realworld decision-making problems inherently involve uncertainty, vagueness, and impreciseness, particularly when human judgments are considered by fuzzy modeling. Fuzzy sets theory has been widely used to provide 
a consistent and reliable mechanism for evaluating the alternatives in MCDM problems with uncertain or vague variables. The VIKOR method as an applicable MCDM technique has recently been applied for solving decision-making problems. Some research, such as Sanayei et al. [35] and Shemshadi et al. [20], extended fuzzy VIKOR and used it for SSP. It aggregated fuzzy rating of DMs and defuzzified the decision matrix in initialization of its methods. In other words, it converted different DM's opinions into one decisionmaking matrix; then, it estimated fuzzy matrix by a precise one. It is logical that estimating the fuzzy numbers by a crisp value would be faced by lack of accuracy. In this study, we keep all data in form of fuzzy numbers during the solving process. Therefore, obtaining distance between fuzzy numbers is required. To do so, unlike some papers (such as [64]), which calculated the distance between fuzzy numbers as a crisp value, we have applied an efficient fuzzy distance measure presented by Sadi-Nezhad et al. [70] to increase accuracy in decision-making process. As another novelty of our study, we solve the problem for each individual DM without aggregating the rating of DMs; then, the group decision-making matrix with using DMs decisions is constructed at the end of the proposed method. Finally, aggregating the results for final decision is carried out with considering different weights for DMs. As mentioned, in our method, data remains in the form of fuzzy numbers during the process; therefore, preference ratio method was applied for ranking fuzzy numbers.

\section{The proposed fuzzy VIKOR}

After explaining some preliminary concepts in Section 3 , in this section, a fuzzy VIKOR based on fuzzy distance and preference ratio is extended. The main contribution of the proposed method is utilizing novel fuzzy distance for measuring distance between fuzzy numbers and well-known preference ratio for ranking fuzzy numbers. Utilization a fuzzy distance [70] instead of a crisp value between fuzzy numbers helps us to increase accuracy and efficiency in analyzing real-world problem.

Let us consider an MADM problem with $m$ alternatives and $n$ criteria. Assume that $k \mathrm{DMs}$ are asked about the performance ratings and the importance weight of the criteria. Ratings of DMs are collected in the form of linguistic variables and then transformed into TFNs. Consider $\tilde{x}_{i j}^{k}$ is as performance rating of the $i$ th alternative with regards to the $j$ th criterion for the $k$ th DM. The weights of criteria have been asked about in the form linguistic variables and then converted into fuzzy numbers. Therefore, $\tilde{W}^{k}$ matrix is the fuzzy importance of the criteria for the $k$ th DM. In addition, the relative fuzzy importance of the $k$ th
DM in decision-making procedure is defined as $\tilde{W}_{k}^{\prime}$. By these definitions, the problem can be represented more formally as follows:

$$
\begin{aligned}
\tilde{D}^{k} & =\left[\begin{array}{cccc}
\tilde{x}_{11}^{k} & \tilde{x}_{12}^{k} & \cdots & \tilde{x}_{1 j}^{k} \\
\tilde{x}_{21}^{k} & \tilde{x}_{22}^{k} & \cdots & \tilde{x}_{2 j}^{k} \\
\vdots & \vdots & \vdots & \vdots \\
\tilde{x}_{i 1}^{k} & \tilde{x}_{i 2}^{k} & \cdots & \tilde{x}_{i j}^{k}
\end{array}\right], \\
\tilde{W}^{k} & =\left[\begin{array}{llll}
\tilde{w}_{1}^{k} & \tilde{w}_{2}^{k} & \cdots & \tilde{w}_{j}^{k}
\end{array}\right], \\
\tilde{W}_{k}^{\prime} & =\left(w_{L k}^{\prime}, w_{M k}^{\prime}, w_{R k}^{\prime}\right),
\end{aligned}
$$

where $\tilde{D}^{k}$ is the fuzzy decision matrix of the $k$ th DM. It has $i$ rows and $j$ columns which are related to alternatives and criteria, respectively. Also, $\tilde{w}_{j}^{k}$ is weight of the $j$ th criterion for the $k$ th DM in form of TFN.

Executive procedure of the proposed method can be designed in four stages including:

1. Preliminary and parameters definition;

2. Applying extended fuzzy VIKOR for each DM;

3. Applying extended fuzzy VIKOR for the group;

4. Final fuzzy ranking of alternatives.

Graphical procedure of the proposed method can be considered as shown in Figure 2.

Stage (1): Preliminary and parameters definition:

- Step 1.1. Selection of a committee of decision makers;

- Step 1.2. Determining the set of criteria for decision-making;

- Step 1.3. Determining the final candidate of alternatives after initial screening;

- Step 1.4. Selecting appropriate linguistic variables and their related fuzzy numbers;

- Step 1.5. Determining weights of decision makers in form of fuzzy numbers;

- Step 1.6. Taking DM's opinion about weights of criteria in form of linguistic variables;

- Step 1.7. Taking DM's opinion about scores of the alternative with respect to criteria;

- Step 1.8. Transferring linguistic variables into appropriate fuzzy numbers.

Stage (2): Applying extended fuzzy VIKOR for each DM:

At this stage, the proposed extended fuzzy VIKOR is utilized for each DM and the parameters $\tilde{R}, \tilde{S}$, and $\tilde{Q}$ are calculated for each of them. By these assumptions, the steps of the proposed algorithm of extended VIKOR in this stage are as follow: 


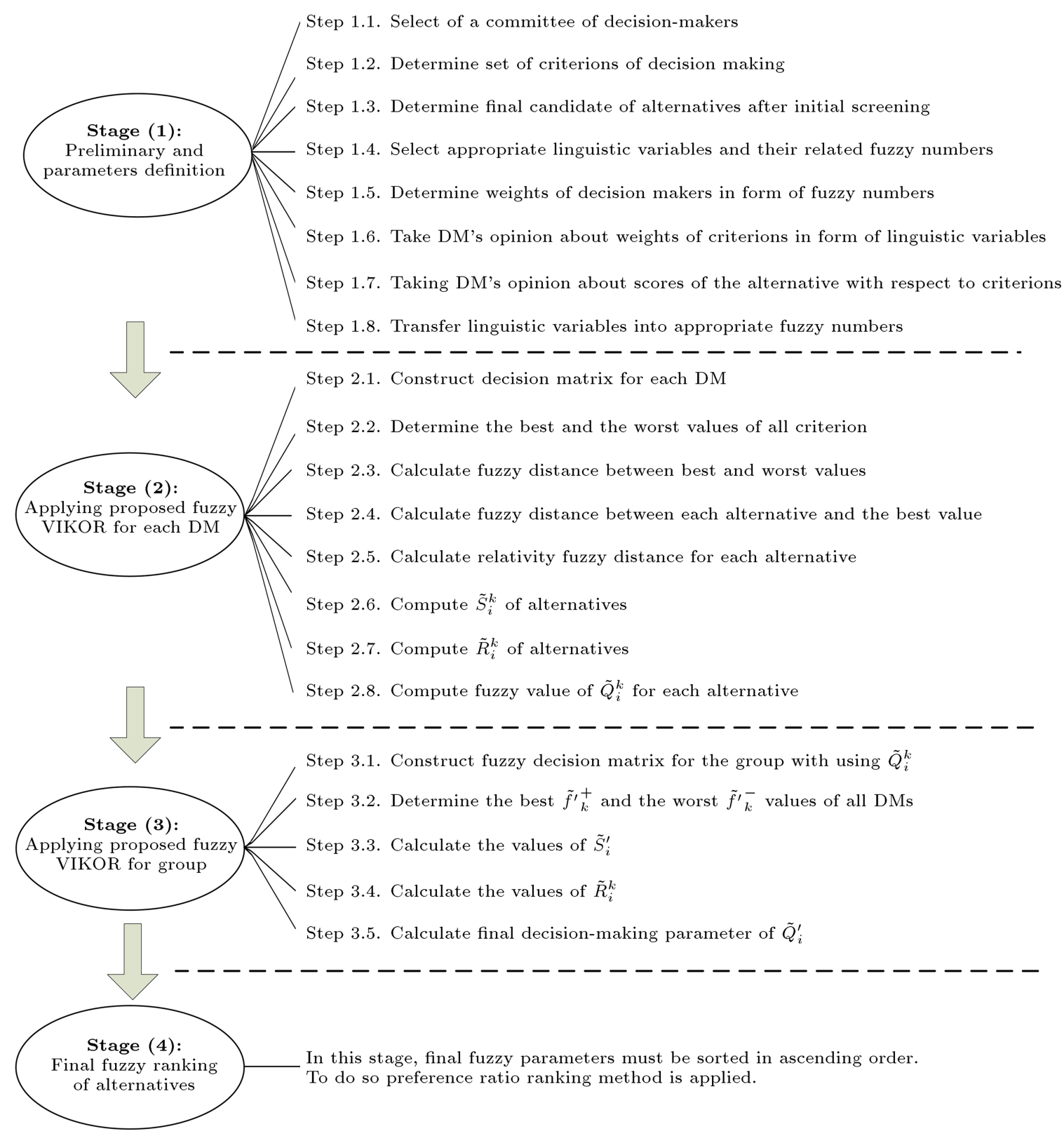

Figure 2. Conceptual framework of the proposed approach.

- Step 2.1. Construct decision matrix for each DM as follows:

$$
\begin{aligned}
\tilde{D}^{k} & =\left[\begin{array}{cccc}
\tilde{x}_{11}^{k} & \tilde{x}_{12}^{k} & \cdots & \tilde{x}_{1 j}^{k} \\
\tilde{x}_{21}^{k} & \tilde{x}_{22}^{k} & \cdots & \tilde{x}_{2 j}^{k} \\
\vdots & \vdots & \vdots & \vdots \\
\tilde{x}_{i 1}^{k} & \tilde{x}_{i 2}^{k} & \cdots & \tilde{x}_{i j}^{k}
\end{array}\right], \\
\tilde{x}_{i j}^{k} & =\left(x_{i j L}^{k}, x_{i j M}^{k}, x_{i j R}^{k}\right) .
\end{aligned}
$$

- Step 2.2. Determine the best $\tilde{f}_{j}^{*}$ and the worst $\tilde{f}_{j}^{-}$values for each criterion, $j=1,2, \cdots, n$ :

$$
\begin{aligned}
& \left\{\begin{aligned}
\tilde{f}_{j}^{* k}= & \left(\max _{i}\left(x_{i j L}^{k}\right), \max _{i}\left(x_{i j M}^{k}\right),\right. \\
& \left.\max _{i}\left(x_{i j R}^{k}\right)\right) ; \quad j \in B \\
\tilde{f}_{j}^{* k}= & \min _{i}\left(x_{i j L}^{k}\right), \min _{i}\left(x_{i j M}^{k}\right), \\
& \left.\min _{i}\left(x_{i j R}^{k}\right)\right) ; \quad j \in C
\end{aligned}\right. \\
& \left\{\begin{aligned}
\tilde{f}_{j}^{-k}= & \left(\min _{i}\left(x_{i j L}^{k}\right), \min _{i}\left(x_{i j M}^{k}\right),\right. \\
& \left.\min _{i}\left(x_{i j R}^{k}\right)\right) ; \quad j \in B \\
\tilde{f}_{j}^{-k}= & \left(\max _{i}\left(x_{i j L}^{k}\right), \max _{i}\left(x_{i j M}^{k}\right),\right. \\
& \left.\max _{i}\left(x_{i j R}^{k}\right)\right) ; \quad j \in C
\end{aligned}\right.
\end{aligned}
$$

where, $B$ and $C$ are benefit and cost criteria index 
sets, respectively;

- Step 2.3. Fuzzy distance by using Eq. (8) is calculated between best and worst values $\mid \tilde{f}_{j}^{* k}-$ $\tilde{f}_{j}^{-k} \mid$ for each criterion;

- Step 2.4. Calculate fuzzy distance between each pair of alternatives and best value for DMs as follows:

$$
\begin{aligned}
& \left|\tilde{f}_{j}^{* k}-\tilde{x}_{i j}^{k}\right| ; \quad(i=1,2, \cdots, m ; j=1,2, \cdots, n), \\
& \text { for } \quad k=1,2, \cdots, K .
\end{aligned}
$$

- Step 2.5. Calculate relativity fuzzy distance for each alternative for DMs as follows:

$$
\begin{aligned}
& \left|\tilde{f}_{j}^{* k}-\tilde{x}_{i j}^{k}\right| /\left|\tilde{f}_{j}^{* k}-\tilde{f}_{j}^{-k}\right|, \\
& (i=1,2, \cdots, m ; \quad j=1,2, \cdots, n), \\
& \text { for } \quad k=1,2, \cdots, K .
\end{aligned}
$$

- Step 2.6. Compute $\tilde{S}_{i}^{k}$ of alternatives for DMs as follows:

$$
\begin{aligned}
\tilde{S}_{i}^{k} & =\sum_{j=1}^{m} \tilde{w}_{j}^{k}\left|\tilde{f}_{j}^{* k}-\tilde{x}_{i j}^{k}\right| /\left|\tilde{f}_{j}^{* k}-\tilde{f}_{j}^{-k}\right|, \\
i & =1,2, \cdots, m, \quad k=1,2, \cdots, K .
\end{aligned}
$$

- Step 2.7. Compute $\tilde{R}_{i}^{k}$ of alternatives for DMs as follows:

$$
\begin{gathered}
\tilde{R}_{i}^{k}=\max _{j}\left\{\left|\tilde{f}_{j}^{* k}-\tilde{x}_{i j}^{k}\right| /\left|\tilde{f}_{j}^{* k}-\tilde{f}_{j}^{-k}\right|,\right. \\
j=1,2, \cdots, m\}, \\
i=1,2, \cdots, m, \quad k=1,2, \cdots, K .
\end{gathered}
$$

In order to implementat Eq. (14), preference ratio ranking method is applied and the biggest relativity fuzzy distance of $\left|\tilde{f}_{j}^{* k}-\tilde{x}_{i j}^{k}\right| /\left|\tilde{f}_{j}^{* k}-\tilde{f}_{j}^{-k}\right|$ for alternatives between criteria is obtained as $\tilde{R}_{i}^{k}$;

- Step 2.8. Compute fuzzy value of $\tilde{Q}_{i}^{k}$ for each alternative and DM as follows:

$$
\tilde{Q}_{i}^{k}=\nu \tilde{S}_{i}^{k}+(1-\nu) \tilde{R}_{i}^{k}
$$

where $\nu$ is a scalar as decision-making, which is considered $\nu=0.5$, in this paper.

Stage (3): Applying the proposed fuzzy VIKOR for group

The obtained $\tilde{Q}_{i}^{k}$ in the previous stage are still TFNs. Applying the proposed fuzzy VIKOR for group decision-making is as the following steps:
- Step 3.1. with using $\tilde{Q}_{i}^{k}(i=1,2, \cdots, m$ and $k=$ $1,2, \cdots, K)$, fuzzy decision matrix for the group is constructed as follows:

$$
\begin{aligned}
\tilde{D}^{\prime} & =\left[\tilde{Q}_{i}^{k}\right]_{m \times K}, \\
\tilde{D}^{\prime} & =\left[\begin{array}{cccc}
\tilde{Q}_{1}^{1} & \tilde{Q}_{1}^{2} & \cdots & \tilde{Q}_{1}^{K} \\
\tilde{Q}_{2}^{1} & \tilde{Q}_{2}^{2} & \cdots & \tilde{Q}_{2}^{K} \\
\vdots & \vdots & \vdots & \vdots \\
\tilde{Q}_{m}^{1} & \tilde{Q}_{m}^{2} & \cdots & \tilde{Q}_{m}^{K}
\end{array}\right], \\
\tilde{Q}_{i}^{k} & =\left(Q_{i L}^{k}, Q_{i M}^{k}, Q_{i R}^{k}\right) .
\end{aligned}
$$

- Step 3.2. Determine the best $\tilde{f}_{k}^{\prime *}$ and the worst $\tilde{f}_{k}^{\prime-}$ values of all DMs $(k=1,2, \cdots, K)$.

$$
\left\{\begin{array}{l}
\tilde{f}_{k}^{\prime *}=\left(\min _{i}\left(Q_{i L}^{k}\right), \min _{i}\left(Q_{i M}^{k}\right), \min _{i}\left(Q_{i R}^{k}\right)\right) \\
\tilde{f}_{k}^{\prime-}=\left(\max _{i}\left(Q_{i L}^{k}\right), \max _{i}\left(Q_{i M}^{k}\right), \max _{i}\left(Q_{i R}^{k}\right)\right)
\end{array}\right.
$$

- Step 3.3. With using fuzzy algebraic operations, the values of $\tilde{S}_{i}^{\prime}$ are calculated as:

$$
\begin{aligned}
\tilde{S}_{i}^{\prime} & =\sum_{k=1}^{K} \tilde{w}_{k}^{\prime}\left|\tilde{f}_{k}^{\prime *}-\tilde{Q}_{i}^{k}\right| /\left|\tilde{f}_{k}^{\prime *}-\tilde{f}_{k}^{\prime-}\right| \\
& i=1,2, \cdots, m
\end{aligned}
$$

where $\tilde{W}_{k}^{\prime}=\left(w_{L k}^{\prime}, w_{M k}^{\prime}, w_{R k}^{\prime}\right)$ is fuzzy weight of the $k$ th $\mathrm{DM}$ in decision-making process;

- Step 3.4. Obtain $\tilde{R}_{i}^{k}$ as follows:

$$
\begin{aligned}
\tilde{R}_{i}^{\prime} & =\max _{k}\left\{\left|\tilde{f}_{k}^{\prime *}-\tilde{Q}_{i}^{k}\right| /\left|\tilde{f}_{k}^{\prime *}-\tilde{f}_{k}^{\prime-}\right|\right\} ; \\
i & =1,2, \cdots, m .
\end{aligned}
$$

This step is utilized same as Step 2.6 in Stage (2);

- Step 3.5. Calculate the final decision-making parameter of $\tilde{Q}_{i}^{\prime}$ for each alternative as:

$$
\tilde{Q}_{i}^{\prime}=\nu \tilde{S}_{i}^{\prime}+(1-\nu) \tilde{R}_{i}^{\prime},
$$

where $\nu$ is a scalar as decision-making, which is considered $\nu=0.5$ in this paper.

Stage (4): Final fuzzy ranking of alternatives:

Final decision-making parameters in VIKOR method are $R, S$, and $Q$, which have been sorted in ascending order. The proposed fuzzy VIKOR decision-making parameters are $\tilde{R}_{i}^{\prime}, \tilde{S}_{i}^{\prime}$, and $\tilde{Q}^{\prime}$, which are TFNs. Therefore, in this stage, the fuzzy parameters are sorted in ascending order. To do so, preference ratio ranking method of fuzzy numbers described in Section 3.4 is applied as algorithm (7). 


\section{Numerical illustration}

In this section, we evaluate performance of our proposed method for SSP. To do so, a numerical example is first applied; then, sensitivity analysis on some parameters is performed to demonstrate validity of the proposed method.

\subsection{A numerical example}

Suppose that a company wants to select a suitable supplier for the main material which strongly affects the production process. In Stage (1) of decision-making process, a committee of four DMs is established. After the initial screening, five candidate suppliers $\left(A_{1}, A_{2}\right.$, $A_{3}, A_{4}$, and $A_{5}$ ) remain for further evaluation. All the four DMs were asked to provide a list of criteria that could be used to evaluate suppliers; ultimately, five criteria consisting of $C_{1}$ : quality, $C_{2}$ : price, $C_{3}$ : lead time delivery, $C_{4}$ : technical level, and $C_{5}$ : flexibility were selected. DM's opinions are considered as linguistic variables. We consider five linguistic variables for the performance rating of the alternative to determine the importance weight of the attributes. These linguistic variables and their TFNs are shown in Table 1.

In order to determine weights of criteria, DMs are asked to rate criteria. Ratings of the importance weight of the criteria provided by each individual DM are presented in Table 2. Also, DMs are asked about rating alternatives with respect to the criteria using linguistic variables mentioned in Table 1 . The performance scores of the alternative suppliers with respect to the five criteria provided by each individual DM are presented in Table 3. These ratings are done by linguistic variables and then linguistic variables are transformed into associated TFNs for criteria and alternatives. At the end of Stage (1), we can construct fuzzy decision matrix for each individual MD. Table 4 shows fuzzy decision matrix for DM1.

After completion of Stage (1), decision-making process is continued by implementing the proposed fuzzy VIKOR for individual DMs in Stage (2). To
Table 2. The importance weight of the criteria provided by the four DMs.

\begin{tabular}{cllll}
\hline Attributes & DM1 & DM2 & DM3 & DM4 \\
\hline $\boldsymbol{C}_{\mathbf{1}}$ & $\mathrm{MH}$ & $\mathrm{H}$ & $\mathrm{H}$ & $\mathrm{VH}$ \\
$\boldsymbol{C}_{\boldsymbol{2}}$ & $\mathrm{M}$ & $\mathrm{M}$ & $\mathrm{MH}$ & $\mathrm{MH}$ \\
$\boldsymbol{C}_{\mathbf{3}}$ & $\mathrm{H}$ & $\mathrm{H}$ & $\mathrm{H}$ & $\mathrm{VH}$ \\
$\boldsymbol{C}_{\boldsymbol{4}}$ & $\mathrm{H}$ & $\mathrm{H}$ & $\mathrm{MH}$ & $\mathrm{VH}$ \\
$\boldsymbol{C}_{\mathbf{5}}$ & $\mathrm{L}$ & $\mathrm{ML}$ & $\mathrm{M}$ & $\mathrm{M}$ \\
\hline
\end{tabular}

do so, the best and the worst values of each criterion are determined by using Eq. (10) and then fuzzy distances $\left(\left|\tilde{f}_{j}^{* k}-\tilde{f}_{j}^{-k}\right|\right)$ between best and worst values for each criterion are calculated by using Eq. (6). Next, fuzzy distances $\left|\tilde{f}_{j}^{* k}-\tilde{x}_{i j}^{k}\right|$ for each pair of alternatives and with respect to each criterion are calculated by Eq. (11). Then, in order to obtain $\tilde{S}_{i}^{k}$ and $\tilde{R}_{i}^{k}$ parameters, values of $\left|\tilde{f}_{j}^{* k}-\tilde{x}_{i j}^{k}\right| /\left|\tilde{f}_{j}^{* k}-\tilde{f}_{j}^{-k}\right|$ are calculated by Eq. (12). Ultimately, fuzzy values of $\tilde{S}_{i}^{k}, \tilde{R}_{i}^{k}$, and $\tilde{Q}_{i}^{k}$ are calculated by using Eqs. (13), (14), and (15). The same steps are performed and the final parameters are achieved for all DMs. The final result of Stage (2) for DM1 is shown in Table 5. All the performed calculations in Stage (2) must be repeated for each individual DM.

Stage (3) of decision-making process is started after obtaining $\tilde{Q}_{i}^{k}$ values for all DMs. In the first step of this stage, group decision-making matrix is established as shown in Table 6 by using $\tilde{Q}_{i}^{k}$ values. With using group decision-making matrix, the best and the worst values for each DM are determined by Eq. (16) and then fuzzy distances of $\left|\tilde{f}_{k}^{\prime *}-\tilde{f}_{k}^{\prime-}\right|$ are calculated. Fuzzy distance values of $\left|\tilde{f}_{k}^{\prime *}-\tilde{Q}_{i}^{k}\right|$ and also relative fuzzy distance values of $\left|\tilde{f}_{k}^{\prime *}-\tilde{Q}_{i}^{k}\right| /\left|\tilde{f}_{k}^{\prime *}-\tilde{f}_{k}^{\prime-}\right|$ for alternatives with respect to DMs are calculated. Using the fuzzy weight vector of the DMs determined as $\tilde{W}_{1}^{\prime}=$ $(0.6,0.7,0.8), \tilde{W}_{2}^{\prime}=(0.4,0.5,0.6), \tilde{W}_{3}^{\prime}=(0.7,0.8,0.9)$, and $\tilde{W}_{4}^{\prime}=(0.7,0.8,0.9)$, the values of $\tilde{S}_{i}^{\prime}$ are calculated by Eq. (17). Also, with using Eqs. (18) and (19), the values of final parameters of decision-making, $\tilde{R}_{i}^{\prime}$ and $\tilde{Q}_{i}^{\prime}$, are calculated as shown in Table 7 .

Table 1. Linguistic variables and their fuzzy numbers.

\begin{tabular}{lcclcr}
\hline \begin{tabular}{c} 
Linguistic variables for \\
rating of \\
\multicolumn{1}{c}{ alternatives }
\end{tabular} & Abbreviation & TFN & $\begin{array}{c}\text { Linguistic variables for } \\
\text { importance weights of } \\
\text { the criteria/DMs }\end{array}$ & Abbreviation & TFN \\
\hline Very Poor & VP & $(1,1,2)$ & Very Low & VL & $(0.1,0.1,0.2)$ \\
Poor & $\mathrm{P}$ & $(2,3,4)$ & Low & $\mathrm{L}$ & $(0.2,0.3,0.4)$ \\
Medium Poor & $\mathrm{MP}$ & $(3,4,5)$ & Medium Low & $\mathrm{ML}$ & $(0.3,0.4,0.5)$ \\
Fair & $\mathrm{F}$ & $(4,5,6)$ & Medium & $\mathrm{M}$ & $(0.4,0.5,0.6)$ \\
Medium Good & $\mathrm{MG}$ & $(6,7,8)$ & Medium High & $\mathrm{MH}$ & $(0.6,0.7,0.8)$ \\
Good & $\mathrm{G}$ & $(7,8,9)$ & High & $\mathrm{H}$ & $(0.7,0.8,0.9)$ \\
Very Good & $\mathrm{VG}$ & $(9,10,10)$ & Very High & $\mathrm{VH}$ & $(0.9,1,1)$ \\
\hline
\end{tabular}


Table 3. The performance scores of the alternatives with respect to the criteria provided by DMs.

\begin{tabular}{|c|c|c|c|c|c|c|c|c|c|c|c|}
\hline & \multicolumn{5}{|c|}{ DM1 } & & \multicolumn{5}{|c|}{ DM2 } \\
\hline & $C_{1}$ & $C_{2}$ & $C_{3}$ & $C_{4}$ & $C_{5}$ & & $C_{1}$ & $C_{2}$ & $C_{3}$ & $C_{4}$ & $C_{5}$ \\
\hline$A_{1}$ & G & $\mathrm{G}$ & $\mathrm{VG}$ & $\mathrm{G}$ & VG & $A_{1}$ & $\mathrm{MG}$ & $\mathrm{MG}$ & $\mathrm{F}$ & $\mathrm{P}$ & $\mathrm{P}$ \\
\hline$A_{2}$ & MG & MG & $\mathrm{G}$ & $\mathrm{F}$ & $\mathrm{G}$ & $A_{2}$ & VG & VG & MG & $\mathrm{MG}$ & $\mathrm{G}$ \\
\hline$A_{3}$ & $\mathrm{G}$ & G & $\mathrm{F}$ & $\mathrm{MG}$ & $\mathrm{G}$ & $\boldsymbol{A}_{3}$ & $\mathrm{G}$ & $\mathrm{VG}$ & $\mathrm{VG}$ & $\mathrm{VG}$ & $\mathrm{VG}$ \\
\hline$A_{4}$ & $\mathrm{~F}$ & $\mathrm{VG}$ & MG & $\mathrm{VG}$ & $\mathrm{VG}$ & $\boldsymbol{A}_{4}$ & MP & G & MG & G & VG \\
\hline \multirow[t]{3}{*}{$A_{5}$} & $\mathrm{VG}$ & $\mathrm{P}$ & $\mathrm{VG}$ & $\mathrm{VG}$ & MP & $A_{5}$ & $\mathrm{G}$ & $\mathrm{MG}$ & $\mathrm{F}$ & $\mathrm{F}$ & $\mathrm{F}$ \\
\hline & \multicolumn{5}{|c|}{ DM3 } & & \multicolumn{5}{|c|}{ DM4 } \\
\hline & $C_{1}$ & $C_{2}$ & $C_{3}$ & $C_{4}$ & $C_{5}$ & & $C_{1}$ & $C_{2}$ & $C_{3}$ & $C_{4}$ & $C_{5}$ \\
\hline$A_{1}$ & G & VG & MG & VG & $\mathrm{F}$ & $A_{1}$ & MG & MG & $\mathrm{G}$ & MP & VG \\
\hline$A_{2}$ & $\mathrm{~F}$ & $\mathrm{G}$ & MP & $\mathrm{MG}$ & $\mathrm{VG}$ & $\boldsymbol{A}_{2}$ & VG & $\mathrm{P}$ & $\mathrm{VG}$ & $\mathrm{F}$ & G \\
\hline$A_{3}$ & VG & G & MP & $\mathrm{MG}$ & MG & $A_{3}$ & G & MG & G & G & $\mathrm{VG}$ \\
\hline$A_{4}$ & $\mathrm{MG}$ & G & G & G & MP & $\boldsymbol{A}_{4}$ & $\mathrm{VG}$ & G & G & $\mathrm{MG}$ & G \\
\hline$A_{5}$ & MG & MG & VG & G & $\mathrm{G}$ & $A_{5}$ & G & $\mathrm{VG}$ & $\mathrm{P}$ & $\mathrm{VG}$ & MG \\
\hline
\end{tabular}

Table 4. The fuzzy decision matrix for the DM1.

\begin{tabular}{clllll}
\hline Weights of & $\mathbf{( 0 . 6 , 0 . 7 , 0 . 8 )}$ & $\mathbf{( 0 . 4 , 0 . 5 , 0 . 6 )}$ & $\mathbf{( 0 . 7 , 0 . 8 , 0 . 9 )}$ & $(\mathbf{0 . 7}, \mathbf{0 . 8}, \mathbf{0 . 9})$ & $(\mathbf{0 . 2}, \mathbf{0 . 3}, \mathbf{0 . 4})$ \\
\cline { 2 - 6 } attributes & \multicolumn{1}{c}{$\boldsymbol{C}_{\mathbf{1}}$} & \multicolumn{1}{c}{$\boldsymbol{C}_{\mathbf{2}}$} & $\boldsymbol{C}_{\mathbf{3}}$ & $\boldsymbol{C}_{\mathbf{4}}$ & \multicolumn{1}{c}{$\boldsymbol{C}_{\mathbf{5}}$} \\
\hline $\boldsymbol{A}_{\mathbf{1}}$ & $(7,8,9)$ & $(7,8,9)$ & $(9,10,10)$ & $(7,8,9)$ & $(9,10,10)$ \\
$\boldsymbol{A}_{\mathbf{2}}$ & $(6,7,8)$ & $(6,7,8)$ & $(7,8,9)$ & $(4,5,6)$ & $(7,8,9)$ \\
$\boldsymbol{A}_{\mathbf{3}}$ & $(7,8,9)$ & $(7,8,9)$ & $(4,5,6)$ & $(6,7,8)$ & $(7,8,9)$ \\
$\boldsymbol{A}_{\mathbf{4}}$ & $(4,5,6)$ & $(9,10,10)$ & $(6,7,8)$ & $(9,10,10)$ & $(9,10,10)$ \\
$\boldsymbol{A}_{\mathbf{5}}$ & $(9,10,10)$ & $(2,3,4)$ & $(9,10,10)$ & $(9,10,10)$ & $(3,4,5)$ \\
\hline
\end{tabular}

Table 5. The final parameters of the proposed fuzzy VIKOR for DM1.

\begin{tabular}{|c|c|c|}
\hline$\tilde{S}_{i}^{k}$ & $\tilde{\boldsymbol{R}}_{\boldsymbol{i}}^{k}$ & $\tilde{\boldsymbol{Q}}_{i}^{k}$ \\
\hline$A_{1}(0.00,0.47,2.46)$ & $(0.00,0.40,1.00)$ & $(0.00,0.57,1.73)$ \\
\hline$A_{2}(0.50,1.85,4.55)$ & $(0.50,1.00,2.00)$ & $(0.50,1.43,3.27)$ \\
\hline$A_{3}(0.47,1.80,4.46)$ & $(0.50,1.00,2.00)$ & $(0.48,1.40,3.23)$ \\
\hline$A_{4}(0.42,1.18,3.32)$ & $(0.50,1.00,2.00)$ & $(0.46,1.09,2.66)$ \\
\hline$A_{5}(0.36,0.80,2.53)$ & $(0.57,1.00,1.75)$ & $(0.47,0.90,2.14)$ \\
\hline
\end{tabular}

After achieving values of $\tilde{Q}_{i}^{\prime}$ for each alternative, sorting of alternatives in ascending order is implemented in Stage (4). As the values of $\tilde{Q}_{i}^{\prime}$ are in the form of fuzzy numbers, preference ratio method is applied for ranking alternatives as described in Eq. (7). The final ranking of alternatives is shown in Table 8. As we can see in Table 8 , the ranking of the five alternatives is $A_{4} \succ A_{1} \succ A_{3} \succ A_{2} \succ A_{5}$ in accordance with $\tilde{Q}_{i}^{\prime}$ in ascending order.

\subsection{Sensitivity analysis}

According to the abovementioned results presented in the previous numerical example, two sensitivity analyses on the parameter $\nu$ and weights of DMs are presented. $\nu$ is a great effective parameter in VIKOR technique to determine the value of the index rank. Normally, the value of $\nu$ is considered as 0.5 . Therefore, a sensitivity analysis by changing value of $\nu$ in the interval $[0,1]$ is performed for the obtained results. The rankings for five alternatives under different $\nu$ values are illustrated in Table 9. As can be seen, when $\nu$ is changed, there are some deviations in ranking of alternatives. $A_{4}$ is the best ranked alternative for $\nu<$ 0.75 ; also, $A_{1}$ has the best rank for $\nu \geq 0.75$. Moreover, $A_{5}$ is the worst ranked alternative for different values of $\nu$.

Another parameters that affect decision-making are weights of DMs. To present a sensitivity analysis on weights of DMs, we consider some compositions of DMs weights and apply the proposed method based on information of the mentioned example. To do so, we use linguistic variables and their TFNs as DMs weights exhibited in Table 1 . The related results according to the different compositions of DMs weights are illustrated in Table 10. It is obvious from Table 10 that for the same given data, the final ranking orders of the alternatives may be influenced by weights of DMs. For instance, if all DMs have the same weights for the evaluation (Problem No. 6 
Table 6. Group decision-making matrix.

\begin{tabular}{|c|c|c|c|c|}
\hline \multirow{2}{*}{$\begin{array}{l}\text { Weights } \\
\text { of DMs }\end{array}$} & $(0.6,0.7,0.8)$ & $(0.4,0.5,0.6)$ & $(0.7,0.8,0.9)$ & $(0.7,0.8,0.9)$ \\
\hline & DM1 & DM2 & DM3 & DM4 \\
\hline$A_{1}$ & $(0.00,0.57,1.73)$ & $(0.71,1.95,5.67)$ & $(0.30,0.89,3.13)$ & $(0.53,1.79,5.80)$ \\
\hline$A_{2}$ & $(0.50,1.43,3.27)$ & $(0.19,0.77,2.19)$ & $(0.49,1.88,7.13)$ & $(0.38,1.27,4.39)$ \\
\hline$A_{3}$ & $(0.48,1.40,3.23)$ & $(0.00,0.13,1.43)$ & $(0.35,1.61,6.60)$ & $(0.04,1.13,4.30)$ \\
\hline$A_{4}$ & $(0.46,1.09,2.66)$ & $(0.26,1.25,4.11)$ & $(0.17,1.29,5.48)$ & $(0.06,0.99,3.94)$ \\
\hline$A_{5}$ & $(0.47,0.90,2.14)$ & $(0.54,1.71,5.28)$ & $(0.26,1.41,6.08)$ & $(0.46,1.58,5.71)$ \\
\hline
\end{tabular}

Table 7. Final parameters of the proposed fuzzy VIKOR for group.

\begin{tabular}{ccc}
\hline$\tilde{\boldsymbol{S}}_{\boldsymbol{i}}^{\prime}$ & $\tilde{\boldsymbol{R}}_{\boldsymbol{i}}^{\prime}$ & $\tilde{\boldsymbol{Q}}_{\boldsymbol{i}}^{\prime}$ \\
\hline $\boldsymbol{A}_{\mathbf{1}}(0.00,0.68,12.62)$ & $(0.00,0.64,5.67)$ & $(0.00,0.66,9.15)$ \\
$\boldsymbol{A}_{\mathbf{2}}(0.00,0.96,14.11)$ & $(0.00,0.50,6.95)$ & $(0.00,0.73,10,53)$ \\
$\boldsymbol{A}_{\mathbf{3}}(0.00,0.66,13.06)$ & $(0.00,0.36,6.43)$ & $(0.00,0.51,9.74)$ \\
$\boldsymbol{A}_{\mathbf{4}}(0.00,0.56,12.88)$ & $(0.00,0.20,5.30)$ & $(0.00,0.38,9.09)$ \\
$\boldsymbol{A}_{\mathbf{5}}(0.00,0.88,15.29)$ & $(0.00,0.26,5.90)$ & $(0.00,0.57,10.60)$ \\
\hline
\end{tabular}

Table 8. Final ranking of alternatives.

\begin{tabular}{cccccc}
\hline & $\mathbf{1}$ & $\mathbf{2}$ & $\mathbf{3}$ & $\mathbf{4}$ & $\mathbf{5}$ \\
\hline By $\tilde{\boldsymbol{S}}_{\boldsymbol{i}}^{\prime}$ & $A_{3}$ & $A_{4}$ & $A_{1}$ & $A_{2}$ & $A_{5}$ \\
By $\tilde{\boldsymbol{R}}_{\boldsymbol{i}}^{\prime}$ & $A_{4}$ & $A_{1}$ & $A_{5}$ & $A_{3}$ & $A_{2}$ \\
By $\tilde{\boldsymbol{Q}}_{\boldsymbol{i}}^{\prime}$ & $A_{4}$ & $A_{3}$ & $A_{1}$ & $A_{2}$ & $A_{5}$ \\
\hline
\end{tabular}

Table 9. Ranking orders of alternatives under different $\nu$ values.

\begin{tabular}{lccccc}
\hline \multirow{2}{*}{ Values of $\boldsymbol{\nu}$} & \multicolumn{5}{c}{ Ranking index } \\
\cline { 2 - 6 } & $\mathbf{1}$ & $\mathbf{2}$ & $\mathbf{3}$ & $\mathbf{4}$ & $\mathbf{5}$ \\
\hline$\nu=0$ & $A_{4}$ & $A_{2}, A_{1}, A_{5}$ & $A_{3}$ & - & - \\
$\nu=0.25$ & $A_{4}$ & $A_{1}$ & $A_{3}$ & $A_{2}$ & $A_{5}$ \\
$\nu=0.5$ & $A_{4}$ & $A_{1}$ & $A_{3}$ & $A_{2}$ & $A_{5}$ \\
$\nu=0.75$ & $A_{1}$ & $A_{4}$ & $A_{3}$ & $A_{2}$ & $A_{5}$ \\
$\nu=1$ & $A_{1}$ & $A_{4}$ & $A_{3}$ & $A_{2}$ & $A_{5}$ \\
\hline
\end{tabular}

in Table 10), $A_{1}$ is the suitable alternative for the considered application example. If DM1 and AM4 have more weights (Problem No. 1), $A_{4}$ is introduced as the best ranked alternative. Also, whenever DM2 and DM3 have more weights (Problem No. 10), $A_{3}$ is the suitable alternative. Thus, the sensitivity analysis shows that the proposed method can represent a more realistic problem by considering different weights for DMs in the decision-making process. It is necessary to mention that weights of DMs can be determined by a higher management level based on their different backgrounds and expertise in problem.

\subsection{Comparison}

In this subsection, we compare our proposed method with two current methods in the field of SSP. To do so, we have applied our proposed method for the considered example in Chen et al. [64] and Sanayei et al. [35] and then compared our result with their result. Comparative results are shown in Table 11.

From the results of Example 1 given in Table 11, it can be observed that Fuzzy TOPSIS [64] and the proposed method suggest the same ranking for suppliers: $A_{2} \succ A_{3} \succ A_{4} \succ A_{1} \succ A_{5}$. This demonstrates the validity of the proposed method. From Example 2, we observe that both fuzzy VIKOR [35] and our proposed method suggest suppliers 4 and 5 as the fourth and fifth choices, respectively. But, for suppliers 1, 2, and 3, our proposed method suggests a different ranking for fuzzy VIKOR [35]. This inconsistency can be understood by the fact that the fuzzy numbers are converted into crisp values and DM's opinions are aggregated into a single matrix in fuzzy VIKOR [35] method, which may produce the consequent loss of information and hence the lack of precision in the final results. The main advantages of our proposed supplier selection method are that we:

1. Keep all data in form of fuzzy numbers during the solving process;

2. Solve the problem for each individual DM without aggregating DMs rating at first;

3. Consider different weights for each DM;

4. Use a simple method to calculate fuzzy distance and to rank fuzzy numbers.

\section{Conclusion}

Supplier evaluation and selection have become a very important issues in today's highly competitive global business environment. In this study, we proposed an extension of fuzzy VIKOR with considering a new efficient, robust, and simple fuzzy distance measure for SSP. To do so, unlike some papers which calculated the distance between fuzzy numbers as a crisp value, we applied an efficient fuzzy distance measure presented 
Table 10. Ranking orders of alternatives under different weights of DMs.

\begin{tabular}{|c|c|c|c|c|c|}
\hline $\begin{array}{c}\text { Problem } \\
\text { no. }\end{array}$ & Weights of DMs & Ranking & $\begin{array}{c}\text { Pro. } \\
\text { no. }\end{array}$ & Weights of DMs & Ranking \\
\hline 1 & $\begin{array}{l}\mathrm{DM} 1=\mathrm{H}, \mathrm{DM} 2=\mathrm{L} \\
\mathrm{DM} 3=\mathrm{M}, \mathrm{DM} 4=\mathrm{H}\end{array}$ & $A_{4} \succ A_{1} \succ A_{3} \succ A_{2} \succ A_{5}$ & 9 & $\begin{array}{l}\mathrm{DM} 1=\mathrm{L}, \mathrm{DM} 2=\mathrm{M} \\
\mathrm{DM} 3=\mathrm{M}, \mathrm{DM} 4=\mathrm{H}\end{array}$ & $A_{4} \succ A_{3} \succ A_{1} \succ A_{2} \succ A_{5}$ \\
\hline 2 & $\begin{array}{l}\mathrm{DM} 1=\mathrm{L}, \mathrm{DM} 2=\mathrm{M} \\
\mathrm{DM} 3=\mathrm{MH}, \mathrm{DM} 4=\mathrm{H}\end{array}$ & $A_{4} \succ A_{1}, A_{3} \succ A_{2} \succ A_{5}$ & 10 & $\begin{array}{l}\mathrm{DM} 1=\mathrm{L}, \mathrm{DM} 2=\mathrm{H} \\
\mathrm{DM} 3=\mathrm{H}, \mathrm{DM} 4=\mathrm{L}\end{array}$ & $A_{3} \succ A_{1} \succ A_{4} \succ A_{2} \succ A_{5}$ \\
\hline 3 & $\begin{array}{l}\mathrm{DM} 1=\mathrm{L}, \mathrm{DM} 2=\mathrm{L} \\
\mathrm{DM} 3=\mathrm{H}, \mathrm{DM} 4=\mathrm{H}\end{array}$ & $A_{1} \succ A_{4} \succ A_{3} \succ A_{5} \succ A_{2}$ & 11 & $\begin{array}{l}\mathrm{DM} 1=\mathrm{L}, \mathrm{DM} 2=\mathrm{L} \\
\mathrm{DM} 3=\mathrm{L}, \mathrm{DM} 4=\mathrm{H}\end{array}$ & $A_{4} \succ A_{3} \succ A_{1} \succ A_{2} \succ A_{5}$ \\
\hline 4 & $\begin{array}{l}\mathrm{DM} 1=\mathrm{H}, \mathrm{DM} 2=\mathrm{H} \\
\mathrm{DM} 3=\mathrm{L}, \mathrm{DM} 4=\mathrm{L}\end{array}$ & $A_{3} \succ A_{1} \succ A_{4} \succ A_{2} \succ A_{5}$ & 12 & $\begin{array}{l}\mathrm{DM} 1=\mathrm{L}, \mathrm{DM} 2=\mathrm{H} \\
\mathrm{DM} 3=\mathrm{L}, \mathrm{DM} 4=\mathrm{L}\end{array}$ & $A_{3} \succ A_{2}, A_{4} \succ A_{1} \succ A_{5}$ \\
\hline 5 & $\begin{array}{l}\mathrm{DM} 1=\mathrm{H}, \mathrm{DM} 2=\mathrm{L} \\
\mathrm{DM} 3=\mathrm{H}, \mathrm{DM} 4=\mathrm{L}\end{array}$ & $A_{1} \succ A_{4} \succ A_{3} \succ A_{5} \succ A_{2}$ & 13 & $\begin{array}{l}\mathrm{DM} 1=\mathrm{L}, \mathrm{DM} 2=\mathrm{L} \\
\mathrm{DM} 3=\mathrm{H}, \mathrm{DM} 4=\mathrm{L}\end{array}$ & $A_{1} \succ A_{4} \succ A_{3} \succ A_{5} \succ A_{2}$ \\
\hline 6 & $\begin{array}{l}\mathrm{DM} 1=\mathrm{M}, \mathrm{DM} 2=\mathrm{M} \\
\mathrm{DM} 3=\mathrm{M}, \mathrm{DM} 4=\mathrm{M}\end{array}$ & $A_{1} \succ A_{3} \succ A_{4} \succ A_{2} \succ A_{5}$ & 14 & $\begin{array}{l}\mathrm{DM} 1=\mathrm{H}, \mathrm{DM} 2=\mathrm{L} \\
\mathrm{DM} 3=\mathrm{L}, \mathrm{DM} 4=\mathrm{L}\end{array}$ & $A_{1} \succ A_{4} \succ A_{3} \succ A_{5} \succ A_{2}$ \\
\hline 7 & $\begin{array}{l}\mathrm{DM} 1=\mathrm{L}, \mathrm{DM} 2=\mathrm{H} \\
\mathrm{DM} 3=\mathrm{L}, \mathrm{DM} 4=\mathrm{H}\end{array}$ & $A_{3} \succ A_{4} \succ A_{2} \succ A_{1} \succ A_{5}$ & 15 & $\begin{array}{l}\mathrm{DM} 1=\mathrm{L}, \mathrm{DM} 2=\mathrm{M} \\
\mathrm{DM} 3=\mathrm{M}, \mathrm{DM} 4=\mathrm{H}\end{array}$ & $A_{4} \succ A_{3} \succ A_{1} \succ A_{2} \succ A_{5}$ \\
\hline 8 & $\begin{array}{l}\mathrm{DM} 1=\mathrm{H}, \mathrm{DM} 2=\mathrm{L} \\
\mathrm{DM} 3=\mathrm{L}, \mathrm{DM} 4=\mathrm{H}\end{array}$ & $A_{4} \succ A_{3} \succ A_{1} \succ A_{2} \succ A_{5}$ & 16 & $\begin{array}{l}\mathrm{DM} 1=\mathrm{H}, \mathrm{DM} 2=\mathrm{L} \\
\mathrm{DM} 3=\mathrm{H}, \mathrm{DM} 4=\mathrm{H}\end{array}$ & $A_{1} \succ A_{4} \succ A_{3} \succ A_{2} \succ A_{5}$ \\
\hline
\end{tabular}

Table 11. Ranking comparisons for examples.

\begin{tabular}{|c|c|c|c|c|}
\hline \multirow[b]{2}{*}{ Alternatives } & \multicolumn{2}{|c|}{ Example 1 } & \multicolumn{2}{|l|}{ Example 2 } \\
\hline & $\begin{array}{c}\text { Fuzzy TOPSIS } \\
\text { (Chen et al. [64]) }\end{array}$ & $\begin{array}{c}\text { Proposed } \\
\text { method }\end{array}$ & $\begin{array}{c}\text { Fuzzy VIKO } \\
\text { (Sanayei et al. [35]) }\end{array}$ & $\begin{array}{c}\text { Proposed } \\
\text { method }\end{array}$ \\
\hline$A_{1}$ & 4 & 4 & 1 & 3 \\
\hline$A_{2}$ & 1 & 1 & 3 & 2 \\
\hline$A_{3}$ & 2 & 2 & 2 & 1 \\
\hline$A_{4}$ & 3 & 3 & 4 & 4 \\
\hline$A_{5}$ & 5 & 5 & 5 & 5 \\
\hline
\end{tabular}

by Sadi-Nezhad et al. [70] to increase accuracy of the decision-making process. Also, we solved the problem for each individual DM without aggregating DMs rating; then, the group decision-making matrix with using DMs decisions was constructed at the end of the proposed method. Finally, aggregation of the results for the final decision was carried out with considering different weights for DMs. To increase accuracy of our method, data remained in the form of fuzzy numbers during the process; therefore, preference ratio method was applied for ranking fuzzy numbers. In the present study, the executive procedure of our proposed fuzzy VIKOR was illustrated by applying it to the problem of supplier selection. At the end of the numerical illustration, two sensitivity analyses on (1) the parameter $\nu$ and (2) weights of DMs were performed. Results showed that the final ranking orders of the alternatives might be influenced by the parameter $\nu$ and weights of DMs. Therefore, the proposed method can model a more realistic problem by considering different weights for DMs in the decisionmaking process.

\section{References}

1. De Boer, L., Labro, E. and Morlacchi, P. "A review of methods supporting supplier selection", European Journal of Purchasing \& Supply Management, 7, pp. 75-89 (2001).

2. Jiang, Z.F., Zhuang, T.Y. and Lin, S.X. "Empirical analysis of the effects of supplier selection and integration on customer satisfaction and business performance", In IEEE International Conference on Management of Innovation and Technology, pp. 931-935 (2006).

3. Ho, W., Xu, X. and Dey, P.K. "Multi-criteria decision making approaches for supplier evaluation and selection: A literature review", European Journal of Operational Research, 202, pp. 16-24 (2010).

4. Xia, W. and Wu, Z. "Supplier selection with multiple criteria in volume discount environments", Omega the 
International Journal of Management Science, 35, pp. 494-504 (2007).

5. Wu, C. and Barnes, D. "A literature review of decisionmaking models and approaches for partner selection in agile supply chains", Journal of Purchasing \& Supply Management, 17, pp. 256-274 (2011).

6. Dickson, G.W. "An analysis of vendor selection systems and decisions", Journal of Purchasing, 2, pp. 5-17 (1966).

7. Weber, C.A., Current, J.R. and Benton, W.C. "Vendor selection criteria and methods", European Journal of Operational Research, 50, pp. 2-18 (1991).

8. Kannan, V.R. and Tan, K.C. "Supplier selection and assessment: their impact on business performance", Journal of Supply Chain Management, 38, pp. 11-21 (2002).

9. FrÖdell, M. "Criteria for achieving efficient contractorsupplier relations", Engineering, Construction and Architectural Management, 18, pp. 381-393 (2011).

10. Ku, C., Chang, C. and Ho, H. "Global supplier selection using fuzzy analytic hierarchy process and fuzzy goal programming", Quality and Quantity, 44, pp. 623-640 (2010).

11. Kahraman, C., Cebeci, U. and Ulukan, Z. "Multicriteria supplier selection using fuzzy AHP", Logistics Information Management, 16, pp. 382-394 (2003).

12. Chai, J., Liu, J.N.K. and Ngai, E.W.T. "Application of decision-making techniques in supplier selection: a systematic review of literature", Expert Systems with Applications, 40, pp. 3872-3885 (2013).

13. Zadeh, L.A. "Fuzzy sets", Information and Control, $\mathbf{8}$, pp. 338-353 (1965).

14. Zadeh, L.A. "The concept of a linguistic variable and its application to approximate reasoning", Information Sciences, 8, pp. 301-357 (1975).

15. Wang, J., Cheng, C. and Kun-Cheng, H. "Fuzzy hierarchical TOPSIS for supplier selection", Applied Soft Computing, 9, pp. 377-386 (2009).

16. Carrera, D.A. and Mayorga, R.V. "Supply chain management: a modular fuzzy inference system approach in supplier selection for new product development", Journal of Intelligent Manufacturing, 19, pp. 1-12 (2008).

17. Keskin, G.A., Ilhan, S. and Özkan, C. "The fuzzy ART algorithm: a categorization method for supplier evaluation and selection", Expert System with Applications, 37, pp. 1235-1240 (2010).

18. Hsu, B., Chiang, C. and Shu, M. "Supplier selection using fuzzy quality data and their applications to touch screen", Expert Systems with Applications, 37, pp. 6192-6200 (2010).

19. BüyükÖzkan, G. and Cifci, G. "A novel fuzzy multicriteria decision framework for sustainable supplier selection with incomplete information", Computers in Industry, 62, pp. 164-174 (2011).
20. Shemshadi, A., Shirazi, H., Toreihi, M. and Tarokh, M.J. "A fuzzy VIKOR method for supplier selection based on entropy measure for objective weighting", Expert Systems with Applications, 38, pp. 12160-12167 (2011).

21. Amindoust, A., Ahmed, S., Saghafinia, A. and Bahreininejad, A. "Sustainable supplier selection: a ranking model based on fuzzy inference system", Applied Soft Computing Journal, 12, pp. 1668-1677 (2012).

22. BüyükÖzkan, G. and Cifci, G. "A novel hybrid MCDM approach based on fuzzy DEMATEL, fuzzy ANP and fuzzy TOPSIS to evaluate green suppliers", Expert Systems with Applications, 39, pp. 3000-3011 (2012).

23. Ozaki, T., Lo, M.C., Kinoshita, E. and Tzeng, G.H. "Decision-making for the best selection of suppliers by using minor ANP", Journal of Intelligent Manufacturing, 23, pp. 2171-2178 (2012).

24. Pang, B. and Bai, S. "An integrated fuzzy synthetic evaluation approach for supplier selection based on analytic network process", Journal of Intelligent Manufacturing, 24, pp. 163-174 (2013).

25. Dursun, M. and Karsak, E.E. "A QFD-based fuzzy MCDM approach for supplier selection", Applied Mathematical Modelling, 37, pp. 5864-5875 (2013).

26. Omurca, S.I. "An intelligent supplier evaluation, selection and development system", Applied Soft Computing, 13, pp. 690-697 (2013).

27. Boran, F.E., Genc, S., Kurt, M. and Akay, D. "A multi-criteria intuitionict fuzzy group decision making for supplier selection with TOPSIS method", Expert Systems with Applications, 36, pp. 11363-11368 (2009).

28. Sharma, S. and Balan, S. "An integrative supplier selection model using Taguchi loss function, TOPSIS and multi criteria goal programming", Journal of Intelligent Manufacturing, 24, pp. 1123-1130 (2013).

29. Ayag, Z. and Samanlioglu, F. "An intelligent approach to supplier evaluation in automotive sector", Journal of Intelligent Manufacturing, 27, pp. 889-903 (2016).

30. Carpinetti, L.C.R. and Junior, F.R.L. "Using combined fuzzy and TOPSIS techniques for supporting supplier selection decision taken", Conference: International Annual EurOMA Conference (European Operations Management Association), 19, Amsterdam (2012).

31. Cao, Q., Wu, J. and Liang, C. "An intuitionsitic fuzzy judgement matrix and TOPSIS integrated multicriteria decision making method for green supplier selection", Journal of Intelligent \& Fuzzy Systems, 28, pp. 117-126 (2015).

32. Opricovic, S. and Tzeng, G.H. "Compromise solution by MCDM methods: a comparative analysis of VIKOR and TOPSIS", European Journal of Operational Research, $\mathbf{1 5 6}$ (2), pp. 445-55 (2004).

33. Opricovic, S. and Tzeng, G.H. "Extended VIKOR method in comparison with outranking methods", European Journal of Operational Research, 178, pp. 514-529 (2007). 
34. Chen, L.Y. and Wang, T.C. "Optimizing partners' choice in IS/IT outsourcing projects: The strategic decision of fuzzy VIKOR", Int. J. Production Economics, 120, pp. 233-242 (2009).

35. Sanayei, A., Mousavi, S.F. and Yazdankhah, A. "Group decision making process for supplier selection with VIKOR under fuzzy environment", Expert Systems with Applications, 37, pp. 24-30 (2010).

36. Ahmad, J., Xu, J., Nazam, M. and Kashif Javed, M. "A fuzzy linguistic VIKOR multiple criteria group decision making method for supplier selection", International Journal of Sciences: Basic and Applied Research (IJSBAR), 19(1), pp. 1-16 (2015).

37. Roostaee, R., Izadikhah, M., Hosseinzadeh Lotfi, F. and Rostamy-Malkhalifeh, M. "A multi-criteria intuitionistic fuzzy group decision making method for supplier selection with VIKOR method", International Journal of Fuzzy System Applications, 2, pp. 1-17 (2012).

38. Jahan, A., Mustapha, F., Yusof Ismail, MD., Sapuan, S.M. and Bahraminasab, M. "A comprehensive VIKOR method for material selection", Materials and Design, 32, pp. 1215-1221 (2011).

39. Liu, H.C., Liu, L. and Wu, J. "Material selection using an interval 2-tuple linguistic VIKOR method considering subjective and objective weights", Materials and Design, 52, pp. 158-167 (2013).

40. Jahan, A. and Edwards K.L. "VIKOR method for material selection problems with interval numbers and target-based criteria", Materials and Design, 47, pp. 759-765 (2013).

41. Wan, S.P., Wang, Q.Y. and Dong, J.Y. "The extended VIKOR method for multi-attribute group decision making with triangular intuitionistic fuzzy numbers", Knowledge-Based Systems, 52, pp. 65-77 (2013).

42. Kuo, M.S. and Liang, G.S. "A soft computing method of performance evaluation with MCDM based on interval-valued fuzzy numbers", Applied Soft Computing, 12, pp. 476-485 (2012).

43. Rezaie, K., Ramiyani, S.S., Nazari-Shirkouhi, S. and Badizadeh, A. "Evaluating performance of Iranian cement firms using an integrated fuzzy AHP-VIKOR method", Applied Mathematical Modelling, DOI: http:// dx.doi.org/10.1016/j.apm.2014.04.003 (2014).

44. Opricovic, S. "Fuzzy VIKOR with an application to water resources planning", Expert Systems with Applications, 38, pp. 12983-12990 (2011).

45. Devi, K. "Extension of VIKOR method in intuitionistic fuzzy environment for robot selection", Expert Systems with Applications, 38, pp. 14163-14168 (2011).

46. Tsai, W.H., Chou, W.C. and Leu, J.D. "An effectiveness evaluation model for the web-based marketing of the airline industry", Expert Systems with Applications, 38, pp. 15499-15516 (2011).

47. Liu, H.C., Wu, J. and Li, P. "Assessment of healthcare waste disposal methods using a VIKOR-based fuzzy multi-criteria decision making method", Waste Management, 33, pp. 2744-2751 (2013).
48. Liu, H.-C., You, J.-X., Fan, X.-J. and Chen, Y.-Z. "Site selection in waste management by the VIKOR method using linguistic assessment", Applied Soft Computing, http://dx.doi.org/10.1016/j.asoc.2014.04.004 (2014).

49. Wang, T.C. and Chang, T.H. "Fuzzy VIKOR as a resolution for multicriteria group decision-making", In The 11th International Conference on Industrial Engineering and Engineering Management, pp. 352356 (2005).

50. Aghajani Bazzazi, A., Osanloo, M. and Karimi, B. "Deriving preference order of open pit mines equipment through MADM methods: Application of modified VIKOR method", Expert Systems with Applications, 38, pp. 2550-2556 (2011).

51. Liu, H.C., Liu, L., Liu, N. and Mao, L.X. "Risk evaluation in failure mode and effects analysis with extended VIKOR method under fuzzy environment", Expert Systems with Applications, 39, pp. 12926-12934 (2012).

52. Kim, Y. and Chung, E.S. "Fuzzy VIKOR approach for assessing the vulnerability of the water supply to climate change and variability in South Korea", Applied Mathematical Modelling, 37, pp. 9419-9430 (2013).

53. Liu, H.C., Mao, L.X., Zhang, Z.Y. and Li, P. "Induced aggregation operators in the VIKOR method and its application in material selection", Applied Mathematical Modelling, 37, pp. 6325-6338 (2013).

54. Peide Liu, P. and Wang, M. "An extended VIKOR method for multiple attribute group decision making based on generalized interval-valued trapezoidal fuzzy numbers", Scientific Research and Essays, 6, pp. 766776 (2011)

55. Sayadi, M.K., Heydari, M. and Shahanaghi K. "Extension of VIKOR method for decision making problem with interval numbers", Applied Mathematical Modelling, 33, pp. 2257-2262 (2009).

56. Park, J.H., Cho, H.J. and Kwun, Y.C. "Extension of the VIKOR method to dynamic intuitionistic fuzzy multiple attribute decision making", Computers and Mathematics with Applications, 65, pp. 731-744 (2013).

57. Ju, Y. and Wang, A. "Extension of VIKOR method for multi-criteria group decision making problem with linguistic information", Applied Mathematical Modelling, 37, pp. 3112-3125 (2013).

58. Yücenur, G.N. and Demirel, N.C. "Group decision making process for insurance company selection problem with extended VIKOR method under fuzzy environment", Expert Systems with Applications, 39, pp. 3702-3707 (2012).

59. Minatoura, Y., Khazaiea, J., Ataei, M. and Javadi, A.A. "An integrated decision support system for dam site selection", Scientia Iranica A, 22, pp. 319-330 (2015).

60. Vahdani, B., Hadipour, H. and Tavakkoli-Moghaddam, R. "Soft computing based on interval valued fuzzy 
ANP-A novel methodology", Journal of Intelligent Manufacturing, 23, pp. 1529-1544 (2012).

61. Shen, K.Y, Yan, M.R. and Tzeng, G.H. "Combining VIKOR-DANP model for glamor stock selection and stock performance improvement", Knowledge-Based Systems, Article in press (2013).

62. Avakh Darestani, S. and Sajadi, S. "A VIKOR-QFD method for supplier selection based on ahp for objective weighting", Trends in Life Sciences, 3, pp. 167-174 (2014).

63. Zimmermann, H.J., Fuzzy Set Theory and Its Applications, second Ed., Kluwer Academic Publishers, Boston, Dordrecht, London (1991).

64. Chen, T.C., Ching, T.L. and Sue, F.H. "A fuzzy approach for supplier evaluation and selection in supply chain management", Int. J. Production Economics, 102, pp. 289-301 (2006).

65. Chakraborty, C. and Chakraborty, D. "A theoretical development on a fuzzy distance measure for fuzzy numbers", Mathematical and Computer Modelling, 43, pp. 254-261 (2006).

66. Voxman, W. "Some remarks on distances between fuzzy numbers", Fuzzy Sets and Systems, 100, pp. 353365 (1998).

67. Chakraborty, C. and Chakraborty, D. "A theoretical development on a fuzzy distance measure for fuzzy numbers", Mathematical and Computer Modelling, 43, pp. 254-261 (2006).

68. Guha, D. and Chakraborty, D. "A new approach to fuzzy distance measure and similarity measure between two generalized fuzzy numbers", Applied Soft Computing, 10(1), pp. 90-99 (2010).

69. Allahviranloo, T., Abbasbandy, S. and Hajighasemi, S. "A new similarity measure for generalized fuzzy numbers", Neural Computing and Applications, 21, pp. 289-294 (2012).

70. Sadi-Nezhad, S., Noroozi-yadak, A. and Makui, A. "Fuzzy distance of triangular fuzzy numbers", Journal of Intelligent and Fuzzy Systems, 25, pp. 845-852 (2013).

71. Asady, B. "Revision of distance minimization method for ranking of fuzzy numbers", Applied Mathematical Modelling, 35, pp. 1306-1313 (2011).

72. Sadi-Nezhad, S. and Damghani, K.K. "Application of a fuzzy TOPSIS method base on modified preference ratio and fuzzy distance measurement in assessment of traffic police centers performance", Applied Soft Computing, 10, pp. 1028-1039 (2010).
73. Modarres, M. and Sadi-Nezhad, S. "Ranking fuzzy numbers by preference ratio", Fuzzy Sets and Systems, 118, pp. 429-436 (2001).

74. Modarres, M. and Sadi-Nezhad, S. "Fuzzy simple additive weighting method by preference ratio", Intelligent Automation and Soft Computing, 11, pp. 235244 (2005).

75. Sadi-Nezhad, S. and Ghaleh Assadi, R. "Preference ratio-based maximum operator approximation and its application in fuzzy flow shop scheduling", Applied Soft Computing, 8, pp. 759-766 (2008).

\section{Biographies}

Amin Mahmoudi is a PhD student in the Department of Industrial Engineering at the Science and Research Branch of Islamic Azad University. He holds both MSc and BSc degrees in Industrial Engineering from Qazvin Branch of Islamic Azad University in Iran. His areas of interest include fuzzy logic, multicriteria decision making, supply chain management, and pricing.

Soheil Sadi-Nezhad received his BS and MS degrees in Industrial Engineering in 1987 and 1989, respectively, from Iran University of Science \& Technology, Tehran, Iran. He received PhD degree in Industrial Engineering (optimization and decision making) in 1999 from Science and Research Branch of the Islamic Azad University, Tehran, Iran. He is currently associate professor in the Industrial Engineering Department of the Science and Research Branch of the Islamic Azad University, Iran. His research interests are in soft computing, fuzzy multiple-criteria decision making, system thinking, fuzzy ranking, FIS, and fuzzy clustering.

Ahmad Makui received his BS degree in 1985 and MS degree in 1991, both in Industrial Engineering. He also received the $\mathrm{PhD}$ degree in Industrial Engineering (Operations Research) in 2000. He is currently Associate Professor in the Industrial Engineering Department at Iran University of Science and Technology, Tehran, Iran. His research interests include production planning, supply chain, decision-making techniques, and mathematical modeling. He has authored numerous papers presented at conferences and published in journals, including JORS, EJOR, PPC, IJAMT, JOMS, ESWA, and MPE. 